\title{
Proposed Automatic Load-Side Power Factor Correction System Algorithm and its Economic Benefits in Battery Based Renewable Energy Systems
}

\author{
Musong Louis Katche ${ }^{1}$, Pierre Tsafack ${ }^{2}$, Emmanuel Tanyi $^{3}$ \\ Graduate Student (FET_UB) ${ }^{1}$, Graduate Student Member, IEEE ${ }^{1}$,Senior Lecturer ${ }^{2}$, Professor ${ }^{3}$ \\ Department of Electrical and Electronic Engineering
}

Faculty of Engineering and Technology (FET), University of Buea (UB)

Buea, South West Region

Cameroon

\begin{abstract}
The low power factor in electrical installations results in high power losses and increased installation costs. This comes as a consequence of the high current flowing through the transmission lines due to high reactive power consumption. Most often, before the installation of renewable energy systems involving battery storage, the load demand is not evaluated in terms of the different load power factors. Because of these diversified power factors for different loads, the overall power factor of the installation will witness a decrease which puts the user at a disadvantage as more charges will be incurred. For these reasons, this paper presents the economic benefits of using an automatic power factor correction system in renewable energy installations. The Arduino microcontroller has been used in the proposal as the main automat. The power factor correction is done by installed capacitor banks connected to the loads automatically using MOSFET (Metal Oxide Semiconductor Field Effect Transistor) power electronic switches and relay blocks with control signals from the microcontroller. A small system was analyzed involving a water pump, fan, television, and a fluorescent lamp. A targeted corrected power factor of 0.99 was used and the results showed that $430.18 \mathrm{~W}$ of power was saved after power factor correction leading to a reduction of $58 \%$ line losses. Also, $\$ 1300$ could be saved by the user on batteries and photovoltaic modules by incorporation the power factor correction system. The proposed correction algorithm was economically beneficial and is therefore strongly recommended to be employed by renewable energy users in particular and the grid-connected individuals in general.
\end{abstract}

Key Words: Power factor correction, Cost Reduction, Microcontroller, Automatic Control, Renewable Energy Systems.

\section{INTRODUCTION}

As energy transition from traditional fossil fuels to green renewable energy sources becomes the order of the day, methods of delivering clean and affordable electrification for all becomes an urgent issue. With electricity, various electrical appliances can be powered such as television, oven, air condition, refrigerator, dryers, fans, water pumps, fluorescent lamps, uninterruptible power supplies, water dispensers and others [1], [2]. Most of these loads are inductive and hence cause low power factor as they are being supplied. Power Factor (PF) is a measure of electrical efficiency and is given by the ratio of active power consumed by the load to apparent power delivered to the load [3], [4]. The power factor is also calculated as the cosine of the angle between the active power and apparent power [5]. More so, it is the cosine of the phase angle between current and voltage in an electric circuit. The variation in power factor also lead to the variation of the active power available to supply the loads [6]. The lower the power factor of an installation, the lower the active power delivered and the higher the reactive power consumption leading to an increase in high current flow [1], [7], [8]. This increase in current flow will demand for larger cable sizes causing high line losses and higher ratings switch gears to protect the installation [9], [10]. This high current flow caused by low power factor will lead to low energy efficiency [11]. Improving energy efficiency is one of the key goals of smart grid initiatives across the globe. In practice, a significant portion of about 5-10\% of generated energy is lost in transmission and distribution systems [5]. This energy loss can be mitigated by improving the power factor of the system. Furthermore, in renewable energy systems, this reduction in active power will lead to additional photovoltaic (PV) modules and increase in battery capacity to supply the available load and meet up with the 
system autonomy. Increasing these energy components means increasing the overall installation and long term maintenance cost of the system [9], [12]. Power factor correction not only reduces system loses but also releases system capacity and improves voltage regulation which enables the utility to provide cost effective and easier services to consumers. Utility operators often charge a penalty for poor power factor. In other to solve this problem, methods must be put in place to correct the power factor of the load automatically during operation so as to maintain it at acceptable limits. Some methods have been presented by different researchers around the globe as will be seen in the proceeding paragraphs.

\subsection{Types of powers and the power triangle}

There exist three different types of powers in power systems namely active power (P), reactive power (Q) and apparent power (S). The active and reactive powers vary continuously with variation in power factor while the apparent power remains constant for any given electrical circuit whenever P and Q varies simultaneously. The three powers are shown in the power triangle of Figure. 1.1 below.

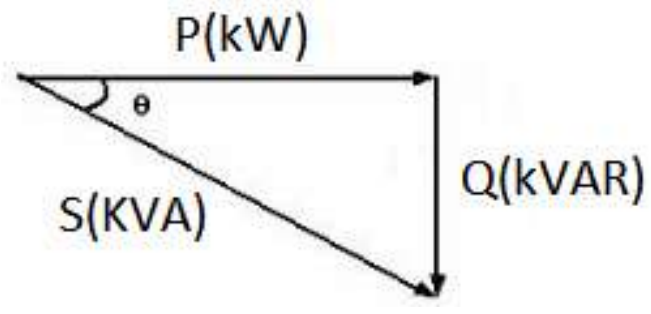

Figure 1.1: Power Triangle [10].

These powers and PF can be calculated analytically and in function of the phase angle $\theta$ using the equations below.

$$
\begin{aligned}
& P F=\cos \theta \\
& P F=\frac{P}{S} \\
& P=S \cos \theta \\
& Q=S \sin \theta \\
& S=V I^{*} \\
& S=\sqrt{P^{2}+Q^{2}}
\end{aligned}
$$

Also, the value of the required capacitor (C) to raise the power factor from $\cos \theta_{1}$ to $\cos \theta_{2} \operatorname{can}$ be calculated using equation (7) below.

$$
\begin{aligned}
& C=\frac{Q_{\text {required }}}{2 \pi f V^{2}} \\
& Q_{\text {required }}=P\left(\tan \theta_{1}-\tan \theta_{2}\right)
\end{aligned}
$$

Where $Q_{\text {required }}$ is the required reactive power needed to be injected by the capacitor bank for the power factor to be corrected, $\mathrm{f}$ is the supply frequency in $(\mathrm{Hz}), \mathrm{V}$ is the supply voltage in $(\mathrm{V})$, and $\mathrm{I}^{*}$ is the complex current flowing in the circuit in (A).

\subsection{Literature Review on Automatic Power Factor Correction Techniques}

Different techniques have been used for power factor correction. Kumar and Rao [13] presented a novel AC/DC converter based on a quasi-active power factor correction (PFC) scheme. In their proposed circuit, they used an auxiliary winding coupled to the transformer of a cascade DC/DC fly back converter to improve the power factor. They placed the auxiliary winding between the input rectifier and a low-frequency filter capacitor to serve as a magnetic switch to drive an input inductor. Because the DC/DC converter is operated at high-switching frequency, the auxiliary windings produce a high frequency pulsating source which lengthens the input current conduction angle thereby reducing the input current harmonics. Their system was such that it eliminates the use of active switch and control circuit for PFC, which results in lower cost and higher efficiency. Jones and Blackwell [4] described a technique for maintaining a synchronous motor at unity power factor from no-load to full-load conditions, assuring peak efficiency. Their results showed that it is feasible to save energy for synchronous motors though the Energy Saver Controller yields power savings of less than 10\%. Allah [5] developed an alienation technique for calculations of original power factor on, active and compensation reactive powers and determination of the required number of capacitor banks required to obtain the desired power factor. He used phase voltage and current signals of power supply to calculate the alienation coefficients. These calculations are performed within one-cycle. Thus, the algorithm is well suited for implementation in a digital reactive power control scheme. This 
scheme is able, accurately to identify the required capacitor rating to get the desired power factor under different loading levels. It does not need any extra equipment as it depends only on the voltage and line-current measurements which are mostly available at the relay location. Alternative transient program (ATP) and MATLAB programs were used to implement the proposed technique. The results showed that it was possible to automatically correct the power factor of the system and maintain it close to unity. Uddin et al., [14] built a microcontroller based automatic power factor correction circuit which was capable of auto-correcting the power factor of the load close to unity by measuring the current power factor and switching in appropriate static capacitors to provide the required reactive power needed for correction. Ali et al., [2] presented a simple and low-cost design of an automatic power factor correction (APFC) system for single phase domestic loads. Their proposed design uses TRIACs to switch capacitor banks in order to correct the power factor of inductive loads. The switching of TRIACs was controlled by an Arduino board. The Arduino was programmed to non-stop monitoring and capable of calculating the power factor of the connecting load by sensing the signal from current transformer (CT), potential transformer (PT) and Zero Crossing Detectors (ZCDs), and keep the power factor of the load above the reference value set to 0.9 by appropriately energizing the capacitors in parallel to the connecting load by turning ON the appropriate TRIAC. The values of power factor along with the current before and after improvement was displayed on LCD. They concluded that the suggested design yielded a reliable output and could be further used in any single phase practical application to maintain the power factor close to unity. Like the work done in [2], Taye in [4] also presented an arduino (ATmega328) based microcontroller, low cost automatic power factor correction system to boost an industrial power factor from 0.66 to 0.92 by switching in capacitors. A similar system was presented in [15]. Ismail and Patel [16] also design a similar system like that in [4] and [15] while using graded capacitors for power factor correction. Sayed et al., [17] proposed an automatic power factor correction for variable inductive loads using a Programmable Logic Controllers (PLC). Their hardware implementation of a three phase inductive load system focused on the automatic correction of power factor using PLC. They used the PLC program, according to control strategy to obtain a pre specified power factor by switching a set of capacitors sized in a binary rate ON or OFF with the help of switching relays and contactors. Rija et al., [18] proposed a low cost Automatic Power Factor Correction (APFC) system to increase the PF of both lagging and leading single- phase loads. They used Arduino Mega 2560 microcontroller to calculate the PF and activate the relays that connect the capacitor/inductor banks to the load in parallel in order to adjust the power factor. They obtained power factors of close to unity for both lagging and leading loads. Tiwari et al., [19], [20] presented a simulated microcontroller based automatic power factor correction system using capacitor banks and their system could maintain the power factor between 0.9 to 0.95 . Jha et al., [21] also presented a microcontroller power factor correction system with PID tunning and MATLAB simulation. Than [22] implemented an automatic power factor correction system using solid state switches (TRIAC) and arduino uno microcontroller. The system was design to maintain the power factor at 0.94 which was achieved by automatically connecting appropriate capacitors as the load changes.

\subsection{Aim and objectives}

The aim of this paper is to propose an algorithm that can be used to design a microcntroller based system that is capable of automatically correcting the power factor of a single phase AC circuit, and also to evaluate the economic importance of implementing such a system in terms of energy saving and cost reduction in a photovoltaic renewable energy system including battery storage (Lead acid batteries).

\section{MATERIALS AND METHODS}

\subsection{Materials to be used}

The following materials will be used in the design of this system. An Arduino Uno microcontroller (ATmega328) will be used as the main controller. This microcontroller has been chosen because of its versatility in accepting both analogue and digital signals as inputs and produces respective digital output control signals. Current sensors and voltage sensors will be used to measure respectively the current and voltage signals and information sent to the Arduino for processing. Also, relay blocks will be used for switching at the level of the power circuit because their contacts are capable of withstanding high voltages of $220 \mathrm{~V}$ to $240 \mathrm{~V}$. These relays will be controlled by power MOSFETs (IRF540), isolated from the microcontroller by optocouplers to avoid damage to the microcontroller caused by an eventual feedback of power from the power source to the Arduino circuitry. Also, diodes will be used for freewheeling at the level of the relay coils. Capacitors will be used as the main components to provide the required reactive power necessary for power factor correction. A liquid crystal display (LCD 20x4) will be used to display the measured quantities.

\subsection{Block diagram of the system}

Figure. 2.1 below shows the proposed block diagram to be used for the system design. 


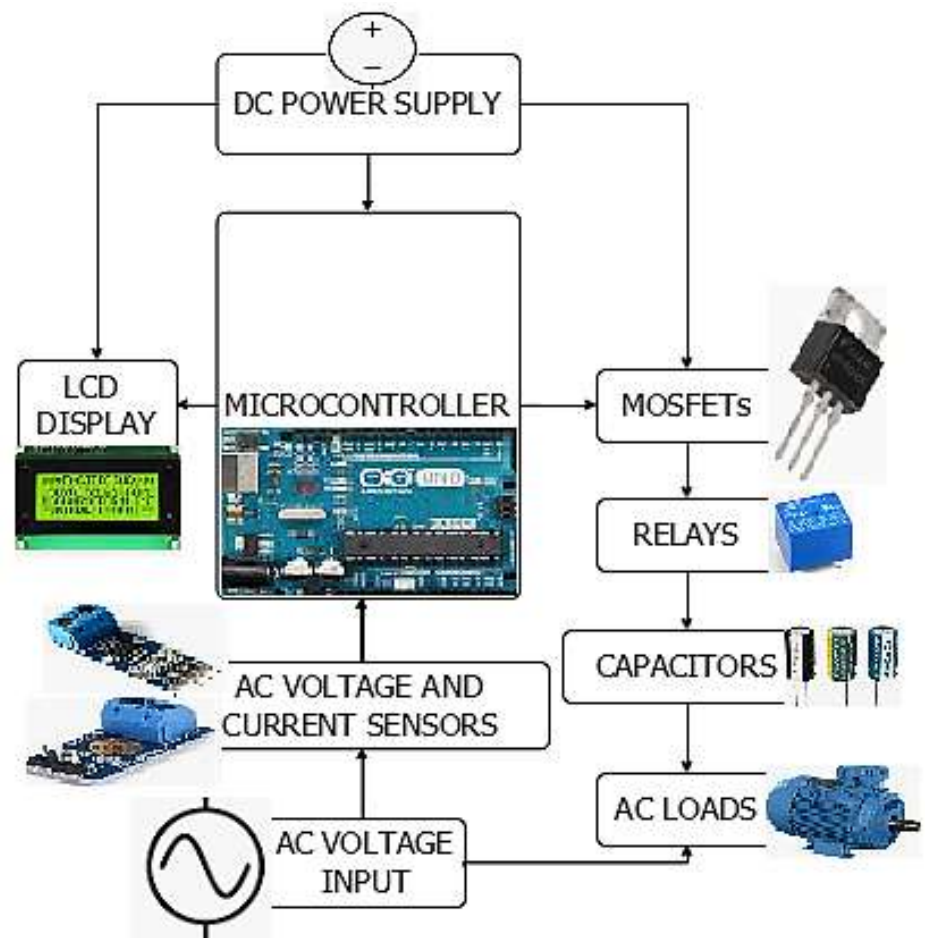

Figure 2.1: Block diagram

\subsection{Flow chart for the control system}

The flow chart of the programming algorithm is presented in Figure 2.2.

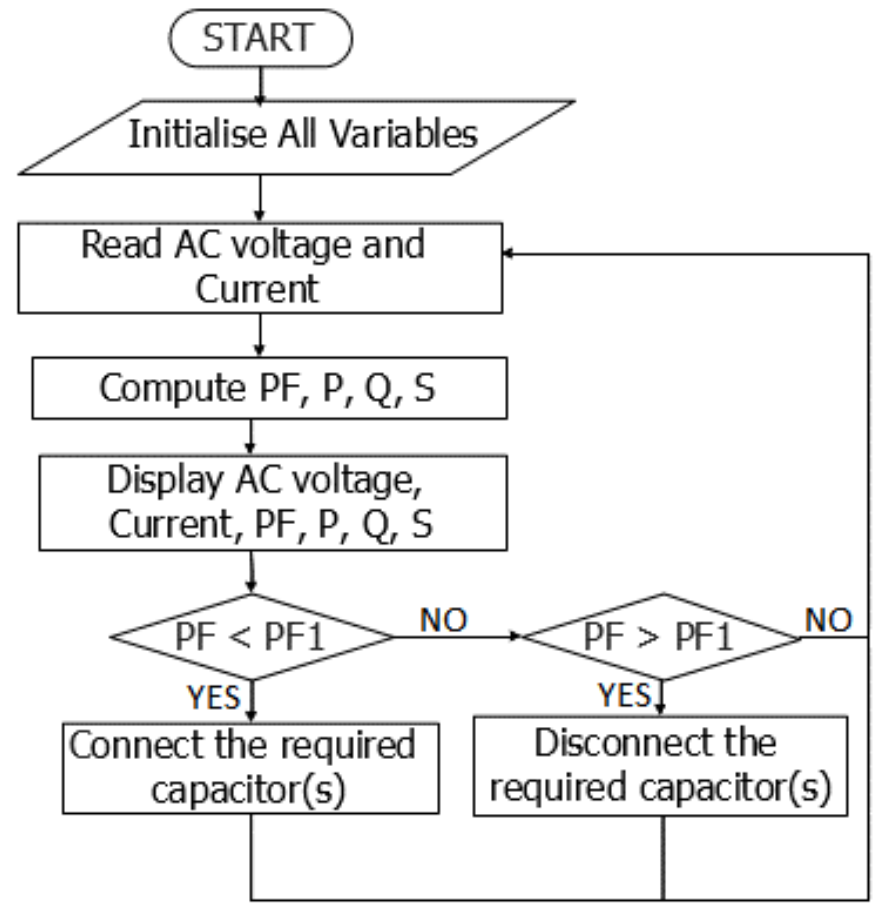

Figure 2.2: System flow chart

From the block diagram of Figure 2.1, the system measures the input AC current and voltage using respectively the current and voltage sensors. This information is then sent to the microcontroller for processing. The microcontroller then uses the current and voltage information to compute the $\mathrm{PF}, \mathrm{P}, \mathrm{Q}$ and $\mathrm{S}$. The value of the newly computed power factor is then compared with the stored power factor (PF1) in the system. If the computed value is different from the stored value, appropriate sets of capacitors are automatically switched and connected in parallel with the loads to correct the power of the system. The switching of these capacitors is done through the power MOSFET (IRF540) switches connected to different relays. The control system is programmed to continuously monitor the system and correcting the power factor as need arises. 
International Journal of Advances in Scientific Research and Engineering (ijasre), Volume 7 (6), 2021

\subsection{Calculating the values of capacitors}

The capacitor values used for the PF correction were calculated using equations (7) and (8). Three capacitor values were obtained for three ranges of power factor variation as shown on Table 2.1 below.

Table 2.1. Calculation of Capacitance

\begin{tabular}{|l|l|l|l|}
\hline S. No. & Variable PF & Target PF & C $(\mathbf{u F})$ \\
\hline 1 & 0.5 & 0.99 & 145 \\
\hline 2 & 0.7 & 0.99 & 80 \\
\hline 3 & 0.9 & 0.99 & 31 \\
\hline
\end{tabular}

\section{RESULTS AND DISCUSSION}

\subsection{Power factor calculation for the loads before correction}

The following loads were first analyzed with their power factors before correction as shown in Table 3.1. below. The values of the power factors used are obtained from [23]-[25]. The calculations are done for a single phase AC voltage of $220 \mathrm{~V}$.

Table 3.1. CALCULATION WITH PF BEFORE CORRECTION.

\begin{tabular}{|c|c|c|c|c|c|c|c|}
\hline S. No. & LOADS & $\mathbf{P}(\mathbf{W})$ & PF & Q (VAR) & S (VA) & I (A) & $\mathbf{I}_{\mathrm{T}}(\mathrm{A})$ \\
\hline 1 & WP & 1188 & 0.75 & 1047.72 & 1584 & 7.2 & \multirow{4}{*}{8.33} \\
\hline 2 & FL & 36 & 0.93 & 14.23 & 38.7 & 0.18 & \\
\hline 3 & FAN & 60 & 0.85 & 37.18 & 70.59 & 0.32 & \\
\hline 4 & TV & 100 & 0.7 & 102 & 142.84 & 0.65 & \\
\hline 5 & TOTAL & 1384 & & 1201.13 & 1832.53 & 8.33 & 8.33 \\
\hline
\end{tabular}

$\mathrm{WP}=$ Water Pump, $\mathrm{FL}=$ Fluorescent Lamp, $\mathrm{I}_{\mathrm{T}}=$ Total current drawn.

\subsection{Power factor calculation for the loads after correction}

The loads were then analyzed with the corrected power factors as shown in Table 3.2 below.

Table 3.2. Calculation with PF after Correction.

\begin{tabular}{|c|c|c|c|c|c|c|c|}
\hline S. No. & LOADS & $\mathbf{P}(\mathbf{W})$ & $\mathbf{P F}$ & $\overline{Q(V A R)}$ & $\overline{S(V A)}$ & I (A) & $\overline{I_{T}(A)}$ \\
\hline 1 & WP & 1188 & 0.99 & 169.29 & 1200 & 5.45 & \multirow{4}{*}{6.35} \\
\hline 2 & FL & 36 & 0.99 & 5.13 & 36.36 & 0.17 & \\
\hline 3 & FAN & 60 & 0.99 & 8.55 & 60.61 & 0.28 & \\
\hline 4 & TV & 100 & 0.99 & 14.25 & 101 & 0.46 & \\
\hline 5 & TOTAL & 1384 & & 197.22 & 1398 & & 6.35 \\
\hline
\end{tabular}

The values of the current drawn by different loads before and after power factor correction are shown in Figure 3.1 below. 


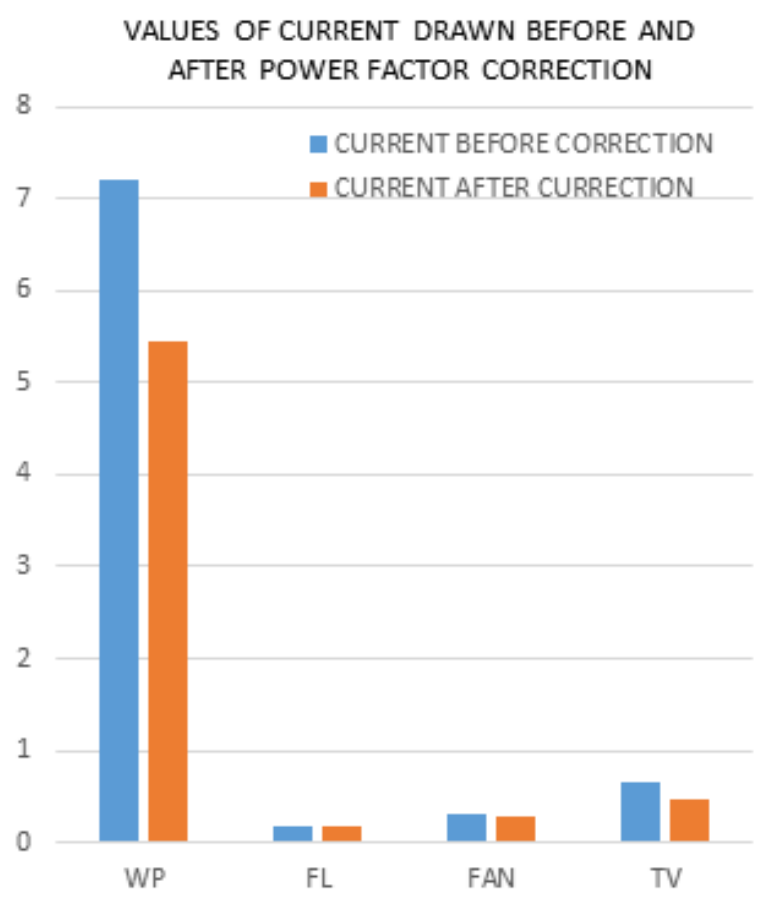

Figure 3.1: Current drawn before and after power factor correction

It is shown that for very low PF, the current drawn by the load is high. This causes high power losses on transmission lines and reduces the overall efficiency of the system. These high values of current may lead to cable destruction if the cross-sectional area of the conductors is small to withstand the current. This always give rise to changing the cables in the installation and also putting in place protective devices that can withstand this current. All these entails adding up to system cost. This problem was solved by incorporation the APFC system at the load side of the power system. The total current drawn before correction was 8.33A and the total current drawn after correction was 6.35A. Performing a power loss ratio on the lines, results showed that the system was able to reduce the line losses by $58 \%$ resulting to more power transmitted to the load.

Figure 3.2 shows that the required capacity to supply the system could be reduced by correcting the PF as $\mathrm{S}$ decreases with increase in PF.

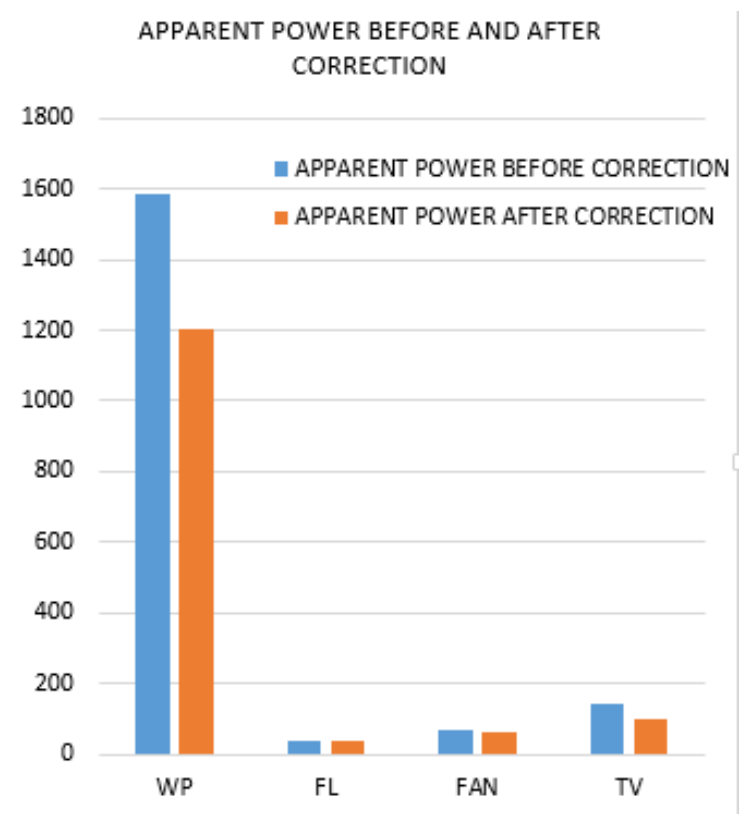

Figure 3.2: Apparent power before and after power factor correction

Figure 3.3 shows the results of the variation of $\mathrm{P}$ and $\mathrm{Q}$ for $\mathrm{S}=1832.53 \mathrm{VA}$. The curves have been drawn using equations (3) and (4). 


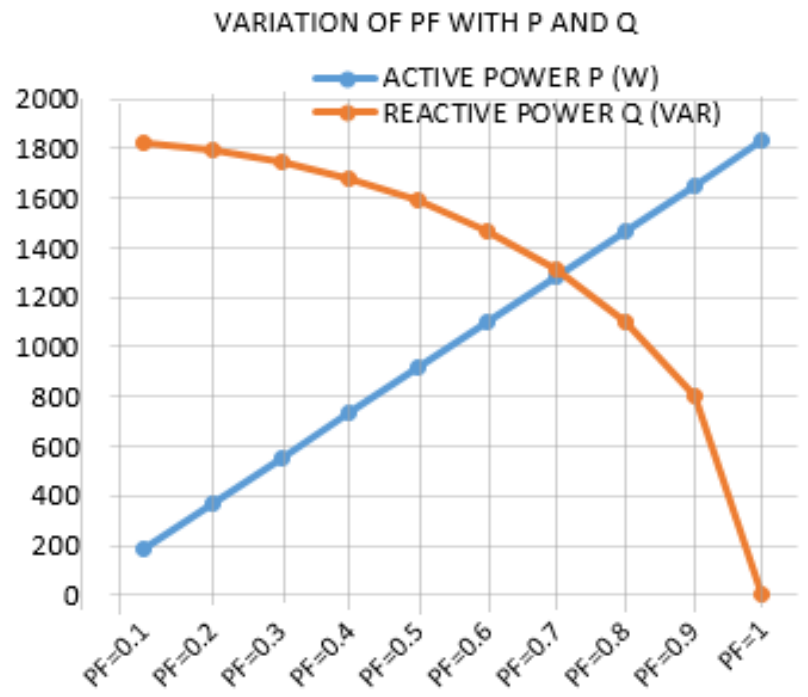

Figure 3.3: Variation of $P F$ with $P$ and $Q$

From the results in Figure 3.3, it is shown that PF has a great influence in the active and reactive powers consumed by appliances. The results show that the higher the $\mathrm{PF}$, the higher $\mathrm{P}$ and the lower $\mathrm{Q}$. Also it is important to note that at unity $\mathrm{PF}, \mathrm{Q}$ is zero and $\mathrm{P}$ is equal to $S$.

\subsection{Cost evaluation}

Table 3.3 shows the corrected values for PF, S and the power that was saved by implementing the correction.

Table 3.3. Summary of the Corrected Values and Power Saved

\begin{tabular}{|l|l|l|l|l|l|l|}
\hline S. No. & PF & $\begin{array}{l}\text { S(VA) Before } \\
\text { Correction }\end{array}$ & $\begin{array}{l}\text { S(VA) After } \\
\text { Correction }\end{array}$ & Change in S(VA) & P(W) Saved \\
\hline 1 & 0.99 & 1832.53 & 1398 & 434.53 & 430.18 \\
\hline
\end{tabular}

Before correcting the PF, the loads were supplied by an inverter with an approximate capacity of 1833 VA. The results showed that the same system could be supplied by an inverter of capacity 1398 VA after correcting the power factor. With this analysis, it is proven that over $430.18 \mathrm{~W}$ of power is now made available for which the user can add more loads without adding the system capacity. This will save cost of purchasing new batteries for storage and PV modules for power generation.

To install $430.18 \mathrm{~W}$ of power, $5 \mathrm{PV}$ modules of $100 \mathrm{~W}$ each and 2 lead acid batteries of 100Ah each are needed. Without considering labour cost and cost of other components but for the batteries and PV modules, the user will spend an additional amount to install the system as shown in TABLE 3.4 below. The battery here has been sized for one day autonomy.

Table 3.4. Cost of Batteries and PV Modules

\begin{tabular}{|l|l|l|l|l|l|}
\hline S. No. & Item & Ratings & Quantity & Unit Cost (\$) & Total Cost (\$) \\
\hline 1 & Lead acid batteries & $12 \mathrm{~V}, 100 \mathrm{Ah}$ & 2 & 275 & 550 \\
\hline 2 & PV modules & $24 \mathrm{~V}, 100 \mathrm{~W}$ & 5 & 150 & 750 \\
\hline $\mathbf{3}$ & Gross Total & & & $\mathbf{1 3 0 0}$ \\
\hline
\end{tabular}

From the cost evaluation, $\$ 1300$ could be saved for batteries and PV modules and $\$ 550$ for batteries only. This amount saved is significant. Therefore, power factor correction plays an important role in cost reduction in renewable energy installations involving battery storage in particular and power systems in general.

\section{CONCLUSION}

Most electrical appliances used have low power factor ratings. This in general causes poor power efficiency because of high power losses incurred. This as shown in this work leads to increase maintenance cost. Low power factor in electrical installations 
results to high power losses and increased installation cost. This work has presented the economic benefits of using an automatic power factor correction system in renewable energy installations. A small system was analyzed involving a water pump, fan, television and a fluorescent lamp. A targeted corrected power factor of 0.99 was used and the results showed that $430.18 \mathrm{~W}$ of power was saved after power factor correction leading to a reduction of 58\% line losses. Also, $\$ 1300$ could be saved by the user on batteries and photovoltaic modules by incorporating the power factor correction system. The proposed correction algorithm was economically beneficial and is therefore strongly recommended to be employed by renewable energy users in particular and the grid connected individuals in general.

\section{REFERENCES}

[1] F. Teddy, S. Gunawan, M. H. Anuar, M. Kartiwi, and Z. Janin, "Development of Power Factor Meter using Arduino," in 2018 IEEE 5th International Conference on Smart Instrumentation, Measurement and Application (ICSIMA), 2018, no. November, pp. 1-4.

[2] W. Ali, H. Farooq, M. Jamil, and R. Taimoor, “Automatic Power Factor Correction for Single Phase Domestic Loads by Means of Arduino Based TRIAC Control of Capacitor Bannks," in 2018 International Conference on Energy Conservation and Efficiency (ICECE), 2018, no. February 2019, pp. 72-76, doi: 10.1109/ECE.2018.8554986.

[3] M. Iorgulescu, "Learning and Training Techniques in Laboratory about Power Factor Compensation," J. Electr. Eng. Electron. Control Comput. Sci. JEEECCS, vol. 3, no. 8, pp. 1-6, 2017.

[4] A. Taye, "DESIGN AND SIMULATION OF AUTOMATIC POWER FACTOR CORRECTION FOR INDUSTRY APPLICATION," Int. J. Eng. Technol. Manag. Res., vol. 5, no. 2, pp. 10-21, 2018, doi: 10.29121/ijetmr.v5.i2.2018.142.

[5] R. A. Allah, “Automatic Power Factor Correction Based on Alienation Technique,” Int. J. Eng. Adv. Technol., no. 4, pp. 194-202, 2014.

[6] R. Dhameliya, K. Domadiya, P. Miyani, H. Savaliya, and P. Jariwala, “AUTOMATIC POWER FACTOR CONTROL USING ARDUINO UNO,” Int. J. Adv. Eng. Res. Dev., vol. 4, no. 4, pp. 270-276, 2017.

[7] L. Rossetto, G. Spiazzi, and P. Tenti, “CONTROL TECHNIQUES FOR POWER FACTOR CORRECTION,” 1994.

[8] S. Rana, N. Miah, and H. Rahman, “Automatic Power Factor Improvement by Using,” Glob. J. Res. Eng. Electr. Electron. Eng., vol. 13, no. 6, 2013.

[9] A. Chandra and T. Agarwal, "Capacitor Bank Designing for Power Factor Improvement," Int. J. Emerg. Technol. Adv. Eng., vol. 4, no. 8, pp. 235-239, 2014.

[10] N. Barsoum, "PROGRAMMING OF PIC MICRO-CONTROLLER FOR POWER FACTOR,” 2007.

[11] I. Ibrik and M. Mahmoud, "Energy Efficiency Improvement by Raising of Power Factor at Industrial Sector in Palestine," Pakistan J. Appl. Sci., vol. 2, no. 9, pp. 907-912, 2002, doi: 10.3923/jas.2002.907.911.

[12] D. B. L. D. Jones, "ENERGY SAVER POWER FACTOR CONTROLLER FOR,” IEEE Trans. Power Appar. Syst., no. 5, pp. 1391-1394, 1983.

[13] G. C. R. Kumar and M. R. C. Rao, "AC / DC Converter with Active Power Factor Correction Applied to DC Motor Drive,” Int. J. Eng. Res. Dev., vol. 1, no. 11, pp. 58-66, 2012.

[14] M. Uddin and A. Al Mahmud, "Design \& Implementation of a Microcontroller Based Automatic Power Factor Rectification System for Different Loads,” 2019 1st Int. Conf. Adv. Sci. Eng. Robot. Technol., pp. 1-6, 2019.

[15] P. Nanda, S. Rathod, B. Halapeti, D. Poojari, G. Math, and S. Jalageri, “Automatic Power Factor Correction Using ATmega328," Int. J. Adv. Eng. Manag., vol. 2, no. 3, pp. 146-149, 2020, doi: 10.35629/5252-0203146149.

[16] H. A. Ismail and G. K. B. Patel, "Automatic Power Factor Correction by Fine Tuning of Graded Capacitors," Int. J. Adv. Res. Ideas Innov. Technol., vol. 3, no. 6, pp. 1425-1431, 2017.

[17] P. V. N. P. Sayed Abdullah Sadat, E. Sreesobha, "Power Factor Correction of Inductive Loads using PLC," 2018, [Online]. Available: https://arxiv.org/abs/1810.12999.

[18] B. M. Rija, M. K. Hussain, and A. M. Vural, "Microcontroller Based Automatic Power Factor Correction for Single-Phase Lagging and Leading Loads,” Eng. Technol. Appl. Sci. Res., vol. 10, no. 6, pp. 6515-6520, 2020.

[19] A. K. Tiwari, D. Sharma, and V. K. Sharma, "Automatic Power Factor Correction Using Capacitive Bank,” Int. J. Eng. Res. Appl., vol. 4, no. 2, pp. 393-395, 2014. 
[20] Utpal, Rishav, and M. Tiwari, “Automatic Power Factor Correction Using Capacitor Banks,” Int. J. Innov. Res. Electr. Electron. Instrum. Control Eng., vol. 4, no. 4, pp. 9-16, 2016, doi: 10.17148/IJIREEICE.

[21] K. K. Jha, B. Mahato, P. Prakash, and K. C. Jana, "Hardware Implementation of Single Phase Power Factor Correction System using Micro-Controller," Int. J. Power Electron. Drive Syst., vol. 7, no. 3, pp. 790-799, 2016, doi: 10.11591/ijpeds.v7.i3.pp790-799.

[22] M. M. Than, "Implementation of Power Factor Correction Using Solid State Switched Capacitors," IOSR J. Electr. Electron. Eng., vol. 11, no. 4, pp. 70-79, 2016, doi: 10.9790/1676-1104027079.

[23] S. Electric, Electrical installation guide. 2018.

[24] Schneider Electric, "Electrical Installation WiKi," 2021. https://www.electricalinstallation.org/enwiki/Example_of_an_installation_before_and_after_power-factor_correction (accessed May 05, 2021).

[25] "The power factor values for the most common equipment and appliances." https://www.calculatorsconversion.com/en/electrical-power-factor-typical-common/ (accessed May 05, 2021).

Emails:

\section{Musong Louis Katche ${ }^{1}$, Pierre Tsafack $^{2}$, Emmanuel Tanyi $^{3}$}

musonglouis@yahoo.com ${ }^{1}$,pierro_tsafack@yahoo.com², emmantanyi@gmail.com³ 